\title{
Is Aortography in Lower Limb Ischaemia Still Abused?
}

\author{
Șqn Ldr D R Andrew
}

FRCS (Glasg), RAF

Senior Registrar

N J P Beasley

FRCS (Ed)

Senior House Officer

\section{S MacPherson}

FRCS

Consultant Surgeon

Department of Surgery, Glenfield General Hospital, Leicester

SUMMARY: A study in 1980 revealed that $38 \%$ of aortograms performed in a series had been referred for inappropriate reasons and only $49 \%$ had been clearly indicated. Recommendations were made to reduce the number of inappropriate investigations.

An audit has been carried out of the aortography referrals made in this unit recently. This has shown that, despite changes in the management of peripheral vascular disease in the intervening years, by following the $\mathscr{\odot}$ recommendations made in the previous paper, the number of inappropriate aortograms has been reduced to a minimum. The recommendations are endorsed.

\section{Introduction}

In 1980 one of the authors (DSM) published an audit of aortography results from 1978 (1). Eighty-eight patients were divided into three groups. Group I consisted of patients whose management had been "influenced clearly" by the aortogram. In Group II the aortogram was considered to be of marginal value, but "probably justifiable". Those patients in whom aortography had been considered to be "inappropriate" had been placed in Group III. This study showed that many aortograms were inappropriate $(38 \%)$ or of marginal value $(11 \%)$, and that many of the inappropriate investigations were ordered by inexperienced clinicians. The conclusions were that aortography should be requested only by senior clinicians involved in the management of peripheral vascular disease, and only for those patients who would be offered surgery if the aortogram showed a lesion suitable for reconstructive surgery. An algorithm was advocated to assist in determining if aortography was required.

Since 1978 important advances have been made in the management of peripheral vascular disease. Most aortograms are performed now by the transfemoral or transaxillary rather than the translumbar approach, and can usually be carried out without general anaesthesia. Percutaneous transfemoral angioplasty (PTA) is now an important mode of treatment and patients who would be unfit for reconstructive surgery might reasonably be referred for angiography to assess their suitability for angioplasty. Modern grafts and microvascular techniques can offer more now for the patient with an ischaemic lower limb. An examination of the relevance of the 1980 recommendations seemed appropriate.

All requests for aortography over a twelve month period and the subsequent patient management we examined. The aim of this paper is to see if thes recommendations made in the 1980 paper had beक्ष̂응 followed, and to assess whether this resulted in a mofe efficient service.

\section{Patients and Methods}

In the present study the case records of 59 patient referred for aortography because of claudication or severe lower limb ischaemia, were examined. The period $\overrightarrow{\partial f}$ follow-up was a minimum of two years. Four sets of records were incomplete or inadequate and were excluded from the study. Three patients underwent more than one $\stackrel{\varrho}{\vec{R}}$ angiographic' procedure: the total number of procedureso응 was 58 . Of these, 43 were transfemoral aortograms (TFAs), 14 were transaxillary aortograms (TAAs) and one? was a translumbar aortogram (TLA).

\section{Results}

Using the same criteria as the earlier study, these 55 patients were categorised into three groups (Table 1). Fifty-three patients were in Group I, two in Group II, and no patients were in Group III. In Group I, 20 patients underwent PTA of which 13 were successful. One of these patients also had reconstructive surgery for a more 3 . distal lesion. In none of the remaining 7 cases was ito possible to traverse the lesion with the angioplasty guide wire. One of these seven patients was treatedo conservatively thereafter, with a reasonable result. The $\vec{D}$ remaining 6 patients proceeded to reconstructive surgery. A total of 34 patients had reconstructive surgery, which was successful in 30 cases. In four cases graft failureoccurred. Two of these patients proceeded to a below $N$ knee amputation and one had an above knee amputation. స్ట The fourth patient died in left ventricular failure. 
Table 1

Outcome in 55 patients undergoing aortography

\begin{tabular}{lccc}
\hline & $\begin{array}{c}\text { Group I } \\
\text { (investigation } \\
\text { justified) }\end{array}$ & $\begin{array}{c}\text { Group II } \\
\text { (probably } \\
\text { justified) }\end{array}$ & $\begin{array}{c}\text { Group III } \\
\text { (investigation } \\
\text { inappropriate) }\end{array}$ \\
\hline Outcome & $\begin{array}{c}13 \text { angioplasties } \\
\text { 34 reconstructed } \\
\text { 6 conservative }\end{array}$ & $\begin{array}{l}\text { 1 } \\
\text { 1 no operation }\end{array}$ & 0 \\
\hline Total & $\mathbf{5 3}(\mathbf{9 6 \%})$ & $\mathbf{2 ( 4 \% )}$ & $\mathbf{0}$ \\
\hline
\end{tabular}

Eight patients had primary conservative management following aortography. Of these, 6 would have been offered surgery had the angiogram shown suitable distal vessels, and were categorised to Group I. Two patients had aortograms showing remediable lesions, but surgery was not carried out. One of these patients had an asymptomatic aneurysm of the profunda femoris artery, and the investigation was carried out to assess the anatomy of the aneurysm. No surgery was carried out after the aortogram, although one year later the aneurysm became painful and was ligated. In the case of the second patient the aortogram showed that reconstruction was possible but would have been extremely difficult. Surgery was advised against because the patient was not fit for a long anaesthetic. In both of these cases it was considered that the aortogram was "probably justifiable", and consequently were categorised to Group II. In no case was the referral for angiography considered to be inappropriate.

The requesting physician in each case was noted. Of the 53 patients in Group I, 42 had been referred for angiography by a consultant vascular surgeon. Three patients had been referred by consultants in general surgery and 8 patients referred by surgeons in training, ( 3 by senior registrars and 5 by registrars) working under the supervision of a vascular surgeon. Both of the patients in Group II were referred for angiography by a consultant vascular surgeon.

\section{Complications}

Four patient developed minor haematomata at the site of cannulation, but none was serious enough to delay discharge from hospital. One patient suffers a transient neuropraxia of the axillary nerve at the site of the axillary artery puncture. Another patient had a PTA performed successfully but later had a massive upper gastrointestinal bleed from oesophageal varices from which he died eight days after the procedure.

\section{Discussion}

This study has confirmed that, by restricting the patients referred for aortography to those who would proceed to corrective treatment in the event of a favourable aortogram result, the number of patients undergoing unnecessary examinations can be reduced substantially.
We believe that screening with duplex Doppler may, by excluding lesions which would be difficult to treat with PTA, reduce the number of requests for angiographya particularly in claudicant patients. It is, however, a timeconsuming process, and in the present series might have reduced the number of requests for aortography by only? one.

By following the algorithm recommended in the $1980^{\circ}$ paper inappropriate referrals can be avoided. With the advent of percutaneous angioplasty, the algorithm can be्क. modified to incorporate this treatment mode (Fig 1). We्क believe that the use if this algorithm is still an effective means of avoiding inappropriate investigations which ares both expensive and potentially dangerous.

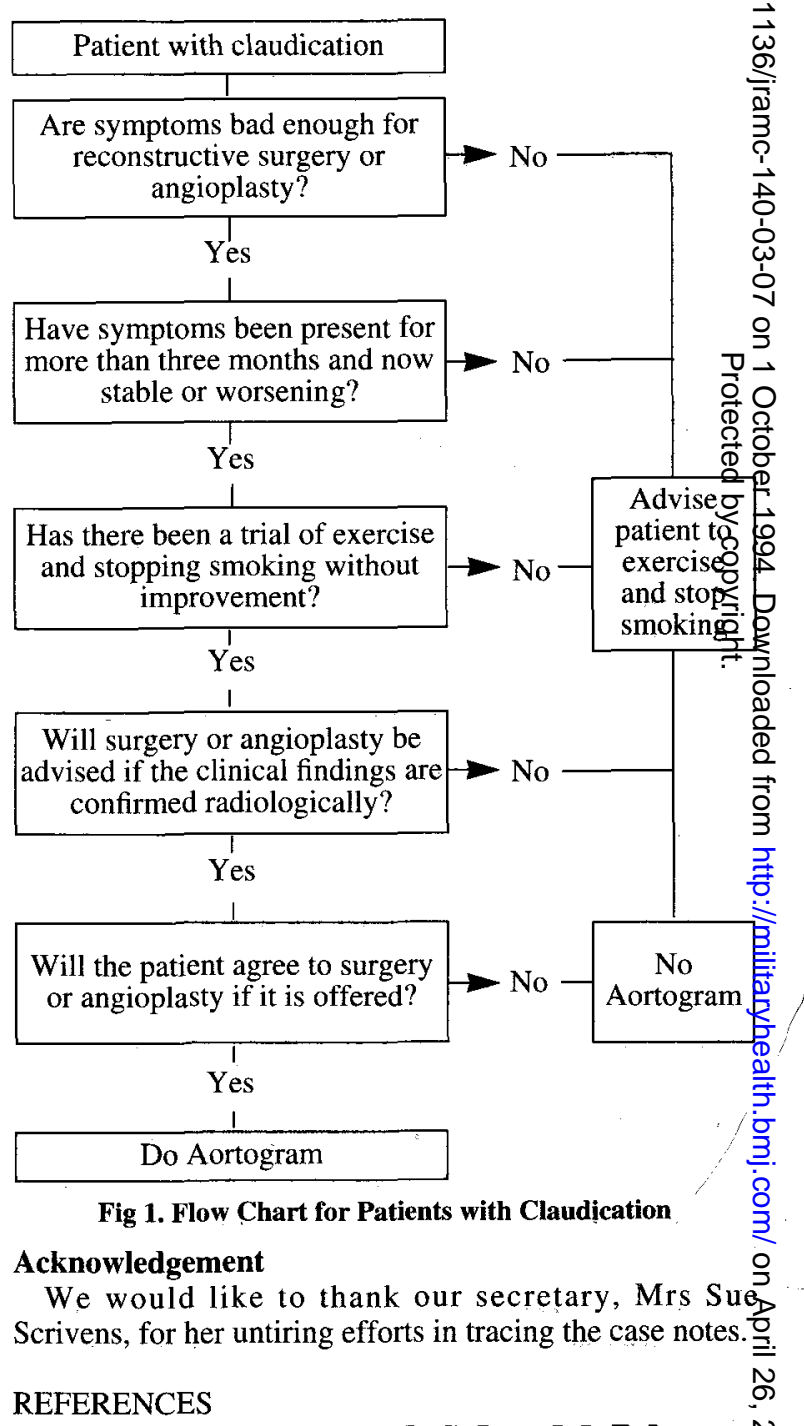

1. MACPherson D S, JAMES D C, BeLl P R F. Is aorto N graphy abused in lower limb ischaemia? Lancet 1980 స్ట 8185: $80-82$. 